\title{
Lateral Infratentorial Cistern
}

National Cancer Institute

\section{Source}

National Cancer Institute. Lateral Infratentorial Cistern. NCI Thesaurus. Code C32939.

A lateral infratentorial subarachnoid cistern. 